\title{
Process Optimization and Adsorptive Mechanism for Reactive Blue 19 Dye by Magnetic Crosslinked Chitosan/MgO/Fe304 Biocomposite
}

Ali H. Jawad ( $\square$ ahjm72@gmail.com )

Universiti Teknologi MARA https://orcid.org/0000-0002-4827-9093

Rangabhashiyam S

SASTRA Deemed University: Shanmugha Arts Science Technology and Research Academy

Ahmed Saud Abdulhameed

Al Mansour University College

Syed Shatir A. Syed-Hassan

Universiti Teknologi MARA

Zeid A. ALOthman

King Saud University

Lee D. Wilson

University of Saskatchewan

\section{Research Article}

Keywords: Chitosan, Magnesium oxide nanoparticles, Adsorption, reactive blue 19 dye, Process optimization

Posted Date: August 30th, 2021

DOI: https://doi.org/10.21203/rs.3.rs-836957/v1

License: (9) This work is licensed under a Creative Commons Attribution 4.0 International License. Read Full License 


\section{Process optimization and adsorptive mechanism for reactive blue 19 dye by magnetic crosslinked chitosan/MgO/Fe3 $\mathrm{O}_{4}$ biocomposite}

Ali H. Jawad ${ }^{\text {a,* }}$, Rangabhashiyam S ${ }^{\mathrm{b}}$, Ahmed Saud Abdulhameed ${ }^{\mathrm{c}}$, Syed Shatir A. Syed-Hassan ${ }^{\mathrm{d}}$ Zeid A. ALOthman ${ }^{\mathrm{e}}$, Lee D. Wilson ${ }^{\mathrm{f}}$

aFaculty of Applied Sciences, UniversitiTeknologi MARA, 40450 Shah Alam, Selangor, Malaysia

${ }^{b}$ Department of Biotechnology, School of Chemical and Biotechnology, SASTRA Deemed University, Thanjavur - 613401, Tamilnadu, India

${ }^{c}$ Department of Medical Instrumentation Engineering, Al-Mansour University College, Baghdad, Iraq

${ }^{\mathrm{d}}$ Faculty of Chemical Engineering, Universiti Teknologi MARA, 40450 Shah Alam, Selangor, Malaysia

${ }^{\mathrm{e}}$ Chemistry Department, College of Science, King Saud University, Riyadh 11451, Saudi Arabia

${ }^{\mathrm{f}}$ Department of Chemistry, University of Saskatchewan, Saskatoon, Saskatchewan S7N 5C9 Canada

Corresponding author:

E-mail: ali288@uitm.edu.my; ahjm72@gmail.com (Ali H. Jawad) 
Abstract: A new biocomposite magnetic crosslinked glutaraldehyde-chitosan/ $\mathrm{MgO} / \mathrm{Fe}_{3} \mathrm{O}_{4}$ (CTS$\mathrm{GL} / \mathrm{MgO} / \mathrm{Fe}_{3} \mathrm{O}_{4}$ ) adsorbent was prepared and applied for the removal of reactive blue 19 ( $\mathrm{RB}$ 19) synthetic textile dye. The prepared CTS-GL/MgO/Fe $3 \mathrm{O}_{4}$ was subjected to the several instrumental characterizations such as XRD, FTIR, SEM-EDX, pH-potentiometric titration, and pHpzc analyses. The influence of the input adsorption parameters such as A: CTS-GL/MgO/ $/ \mathrm{Fe}_{3} \mathrm{O}_{4}$ dosage, B: initial solution $\mathrm{pH}, \mathrm{C}$ : process temperature, and $\mathrm{D}$ : contact time on $\mathrm{RB} 19$ removal efficiency was statistically optimized using Box-Behnken design (BBD). The analysis of variance (ANOVA) indicates the presence of five significant statistical interactions between input adsorption parameters i.e. ( $\mathrm{AB}, \mathrm{AC}, \mathrm{AD}, \mathrm{BC}$, and $\mathrm{BD})$. The adsorption kinetic and equilibrium study reveals a good to the pseudo-second-order model, and multilayer adsorption as proven by Freundlich isotherm model, respectively. The maximum adsorption capacity of CTS$\mathrm{GL} / \mathrm{MgO} / \mathrm{Fe}_{3} \mathrm{O}_{4}$ towards $\mathrm{RB} 19$ was found to be $193.2 \mathrm{mg} / \mathrm{g}$ at $45^{\circ} \mathrm{C}$. This work highlights the development of feasible and recoverable magnetic biocompsite adsorbent with desirable adsorption capacity towards textile dyes with good separation ability by using an external magnetic field.

Keywords: Chitosan; Magnesium oxide nanoparticles; Adsorption; reactive blue 19 dye; Process optimization 


\section{Introduction}

The industrial sectors of papermaking, textile, plastic, cosmetics, and printing industries are the major consumers of the synthetic dyes manufactured globally and acts as the foremost contributors of effluents contaminated with dyes [1]. Annually, many dyes undergoing industrial activities are discharged directly into water bodies without treatment can cause a complicated problems in the environment [2]. The presence of chemically stable and non-biodegradable dyes in high concentrations in water bodies represents a serious threat to the environment and living beings [3]. The colored effluent diminishes the penetration of sunlight and solubility of gas, interferes with the photosynthesis, increased chemical oxygen demand, and biological oxygen demand and more turbidity affect the aquatic biota [4]. Apart from the environmental effects, the organic dyes cause health hazards to human such as vomiting, respiratory tract irritation, increased heart rate, allergy, liver, and kidney damage, problems in the central nervous system, alteration in DNA structure consequence to induced lesions and cancer, gene mutation [5].

Reactive blue 19 (RB19) is one of the important commercial textile dyes belongs to the vinylsulfone azo dye [6]. In recent years, RB 19 reported as a hazardous pollutant, exists in water bodies due to highly solubility, resist degradation, and remains even after effluent treatment plants, in addition to harmful effects such as liver damage, skin problem, and induce weak mutagenic effect [7]. To overcome the problems associated with organic dyes, various treatment techniques such as membrane separation [8], ultrafiltration [9], flocculation [10], microbial degradation [11], photodegradation, [12] and adsorption [13] have been applied for the removal of harmful textile dyes. Nevertheless, the approach of the adsorption technique demonstrated with a simplicity in design, efficiency, and easy handling [14]. However, the efficiency of the adsorption process 
depends mainly on the nature, structure, functionality, particle size, and surface area of the applied adsorbent.

Chitosan (CTS) is a linear form of natural carbohydrate polymer and considered as a second abundant biopolymer obtained from chitin deacetylation [15]. CTS is one of the most explored polymers as adsorbent in the water remediation due to its unique molecular structure that contains amine and hydroxyl functional groups [16]. Moreover, CTS offers various merits in water pollutant removal with potential characteristics of low-cost, biodegradable, biocompatible, and functionality with preferable adsorption capacity [17]. Nevertheless, the native CTS exhibits many technical problems in wastewater treatment technology such as solubility in acidic environment, compressibility under high pressure, high swelling index, in addition to the adsorbent powder recovery during and post treatment process [18, 19]. Therefore, CTS requires further physicochemical modification to be more qualified adsorbent material for wastewater treatment.

The abundancy of amino and hydroxyl active functional groups on the surface of CTS offers unlimited number of useful modifications for diverse applications. Crosslinking reaction is one of the most feasible modification methods to improve the molecular structure, chemical stability, functionality, and hydrophobicity [20]. Among numerous crosslinking agents, glutaraldehyde (GL) presents itself as a feasible cross-linking agent capable for creating a robust connection and irreversible network between CTS's moieties via Schiff's-base system [21]. Composting CTS with nanostructured metal oxide is another interesting approach to improve the CTS's thermal and chemical stability, surface hydrophobicity, and surface area [22]. Among the various nanostructured metal oxides used to design hybrid CTS's biocomposite derivatives, magnesium oxide $(\mathrm{MgO})$ is an interesting nanoscale metal oxide to develop a multi-functional biocomposites (CTS/MgO) due to its unique characteristics including biocompatibility, high 
adsorption capability, non-toxicity, chemical stability, and large surface area-to-volume ratio [23, 24]. In recent years, $\mathrm{CTS} / \mathrm{MgO}$ biocomposites have been received a great interest in several applications such as wastewater treatment [25], food packaging [26], bone regeneration [27], defluoridation of water [28], genosensor [29], and biocatalyst [30]. Recently, new horizons are open for researchers to develop magnetically-biocomposite-based adsorbent and their potential application in wastewater treatment. In this regard, producing a magnetic CTS's biocomposite derivatives as a promising technique to collect the applied adsorbents during and post treatment process by applying external magnetic field and without using any conventional filtration or separation technique [31].

Therefore, the aim of this research work is to develop a recoverable, chemically stable, hydrophobic, and multi-functional absorbent of magnetic biocomposite CTS's derivative. To fulfil this aim, a magnetic crosslinked chitosan-glutaraldehyde/ $\mathrm{MgO} / \mathrm{Fe}_{3} \mathrm{O}_{4}\left(\mathrm{CTS}-\mathrm{GL} / \mathrm{MgO} / \mathrm{Fe}_{3} \mathrm{O}_{4}\right)$ was fabricated to be a potential adsorbent for adsorptive removal of RB19 dye from aqueous environment. The adsorption key parameters were statistically optimized using Box-Behnken design (BBD) and validated by analysis of variance (ANOVA). Furthermore, the adsorption experimental data were fitted to several kinetic and isotherm models, and the mechanism of RB19 adsorption using CTS-GL/MgO/Fe $\mathrm{O}_{4}$ was proposed. 
2. Materials and methods

\subsection{Reagents and materials}

The chitosan biopolymer (CTS) with deacetylation degree of $\geq 75 \%$ and medium molecular weight was purchased from Sigma-Aldrich. Iron (III) chloride hexahydrate $\left(\mathrm{FeCl}_{3} \cdot 6 \mathrm{H}_{2} \mathrm{O}\right.$ molecular weight of $270.3 \mathrm{~g} / \mathrm{mol})$ and Iron (II) chloride tetrahydrate $\left(\mathrm{FeCl}_{2} .4 \mathrm{H}_{2} \mathrm{O}\right.$, molecular weight of $198.81 \mathrm{~g} / \mathrm{mol}$ ) was supplied from $\mathrm{HmbG}$ and Bendosen Laboratory Chemicals, respectively. Reactive Blue 19 (RB19; CAS number - 2580-78-1; C.I. number - 61,200; Molecular mass $-626.54 \mathrm{~g} / \mathrm{mol}$ and $\lambda_{\max }=595 \mathrm{~nm}$ ) commercially referred as Remazol brilliant blue R was ordered from ACROS, Organics. All chemical reagents used for the experiments were of analytical grade and used directly without any further purification. The procedures in the present study of the preparation of aqueous solutions and cleaning procedures were carried out using ultrapure water.

\subsection{Preparation of CTS-GL/MgO/ $\mathrm{Fe}_{3} \mathrm{O}_{4}$ biocomposite}

For the preparation of CTS-GL/MgO/Fe ${ }_{3} \mathrm{O}_{4}, 1 \mathrm{~g}$ flakes of CTS and $1 \mathrm{~g}$ of $\mathrm{MgO}$ nanoparticles were added to the $50 \mathrm{~mL}$ of $5 \%$ acetic acid solution. The mixture was subjected to gentle stirring at room temperature for $24 \mathrm{~h}$ to attain complete CTS dissolving and $\mathrm{MgO}$ nanoparticles incorporation in CTS molecular structure. Further, $3.9 \mathrm{~g}$ of $\mathrm{FeCl}_{3} .6 \mathrm{H}_{2} \mathrm{O}$ and $2.7 \mathrm{~g}$ of $\mathrm{FeCl}_{2} \cdot 4 \mathrm{H}_{2} \mathrm{O}$ added to $10 \mathrm{~mL}$ distilled water, and then the content transferred to $\mathrm{CTS} / \mathrm{MgO}$ solution and kept under mild agitation for $1 \mathrm{~h}$. A plastic syringe needle (10 mL capacity) was used to inject the resultant viscous solution into $1000 \mathrm{~mL}$ of $2 \mathrm{M}$ sodium hydroxide solution under mild agitation, and immediate formation of CTS/MgO/Fe ${ }_{3} \mathrm{O}_{4}$ beads was observed. The obtained CTS/MgO/Fe $\mathrm{O}_{4}$ beads were gently washed with distilled water in such a way to remove the residual sodium 
hydroxide solution. The next step of crosslinking was carried out using $100 \mathrm{~mL}$ of $2 \%$ glutaraldehyde added to the $\mathrm{CTS} / \mathrm{MgO} / \mathrm{Fe}_{3} \mathrm{O}_{4}$ beads under the condition of $40{ }^{\circ} \mathrm{C}$ in thermal water bath shaker for $2 \mathrm{~h}$. Then, the CTS-GL/MgO/Fe $3 \mathrm{O}_{4}$ beads were washed with distilled water and air dried, before being crashed into fine particles with certain particle size $\leq 250 \mu \mathrm{m}$. The final product $\mathrm{CTS}-\mathrm{GL} / \mathrm{MgO} / \mathrm{Fe}_{3} \mathrm{O}_{4}$ powder was employed for the adsorption experiments. The preparation steps of CTS-GL/MgO/Fe $\mathrm{O}_{4}$ beads are given in Fig. 1.

\subsection{Characterization and instrumentation}

Crystalline property of the CTS-GL/MgO/ $/ \mathrm{Fe}_{3} \mathrm{O}_{4}$ were examined using X-ray diffraction analysis (XRD, X'Pert PRO, PAnalytical). Fourier transform infrared spectroscopy (FT-IR) characterization was used to analyze chemical properties and to check the functional groups of CTS-GL/MgO/Fe $3 \mathrm{O}_{4}$ biocomposite before and after RB19 interactions (Perkin-Elmer, Spectrum RX I). Scanning electron microscopy - Energy dispersive x-ray (SEM-EDX) analysis was carried out to examine the textural characteristics and quantitative chemical composition analysis of CTS$\mathrm{GL} / \mathrm{MgO} / \mathrm{Fe}_{3} \mathrm{O}_{4}$ and $\mathrm{RB} 19$ loaded CTS-GL/MgO/Fe $3 \mathrm{O}_{4}$ (Zeiss Supra $40 \mathrm{VP}$, Germany). The specific surface area measurement $\left(\mathrm{S}_{\mathrm{BET}}\right)$ and pore volume of CTS-GL/MgO/Fe $3 \mathrm{O}_{4}$ were deduced through Micromeritics ASAP 2060 analyzer. The point of zero charge $\left(\mathrm{pH}_{\mathrm{pzc}}\right)$, and amine content (- $\mathrm{NH}_{2}$ ) of CTS-GL/MgO/Fe $3 \mathrm{O}_{4}$ were determined according to the procedures reported by Dalvand et al. [32], and Vieira, and Beppu [33], respectively. 


\subsection{Optimization process}

To evaluate the optimum adsorption conditions, and to achieve the highest adsorptive removal performance, the response surface methodology (RSM) approach with the Box-Behnken Design (BBD) was applied as the potential optimization tool. The BBD model illustrates the influence of adsorption independent variables of individual or mutual interaction with each other. Further, BBD model not only examines the impact of independent variables, but also generates an empirical model that explains the appropriate quantity of process [34]. The modeling and optimization of the adsorption of RB19 onto CTS-GL/MgO/Fe $3 \mathrm{O}_{4}$ from an aqueous system conducted by means of regression test and graphically presented using Design-Expert software (version 13, Stat-Ease, Minneapolis, USA). The experiment trails from the approach of the one variable at a time showed significant influence on the dye removal using the adsorption parameters of CTS-GL/MgO/Fe $\mathrm{O}_{4}$ dosage (A), initial solution $\mathrm{pH}(\mathrm{B})$, process temperature (C), and contact time (D). Therefore, these process parameters were selected as input variables for BBD investigation towards the adsorption of RB19, and whereas the RB19 removal efficiency (\%) is the response (Y). The adsorption experiments were performed according to the BBD model. The BBD model presents each independent variable at three different levels of $-1,0$ and +1 presents low, medium, and high values, totally of four variables and design of experiment comprised of 29 experimental runs, whose five replications at the central level for error calculation was selected. The coded and levels of independent variables in BBD are given in Table 1. According to BDD model, the relationship between the response variable and independent variables was elucidated using the second-order nonlinear polynomial numerical expression of quadratic order as mentioned in eq. (1).

$$
Y=\beta_{0}+\sum \beta_{i} X_{i}+\sum \beta_{i i} X_{i}^{2}+\sum \sum \beta_{i j} X_{i} X_{j}
$$


where $Y$ is an objective for the optimization of the response (RB19 removal (\%)); $X_{i}$ and $X_{j}$ are the coded variable; $\beta_{0}, \beta_{i}, \beta_{i i}, \beta_{i j}$ are the constant coefficient, coefficient of linear effect, coefficient of quadratic effect, and coefficient of the interaction effect.

The design comprised 29 runs according to BBD model for the optimization of independent factors such as A: CTS-GL/MgO/Fe ${ }_{3} \mathrm{O}_{4}$ dosage (0.02-0.1 g), B: initial solution $\mathrm{pH}$ (4.0-10.0), C: process temperature $\left(30-60^{\circ} \mathrm{C}\right)$ and $\mathrm{D}$ : contact time (10-40 $\left.\mathrm{min}\right)$ on the RB19 removal efficiency $(\%)$. The actual BBD experimental design matrix and RB19 removal (\%) are recorded in Table 2. A desired amount of CTS-GL/MgO/Fe $3 \mathrm{O}_{4}$ transferred to $100 \mathrm{~mL}$ of $100 \mathrm{mg} / \mathrm{L}$ initial concentration of $\mathrm{RB} 19$ in Erlenmeyer flasks $(250 \mathrm{~mL})$. The stoppered Erlenmeyer flasks were subjected to agitation using water bath shaker (WNB7-45, Memmert, Germany) at $100 \mathrm{rpm}$ agitation speed. After the adsorption process, the separation of CTS-GL/MgO/Fe $3 \mathrm{O}_{4}$ from aqueous solution was firstly done by using an external magnetic bar, before using $0.45 \mu \mathrm{m}$ syringe filter to ensure there is no ultrafine particles were suspended in the analyte solution which may cause an error in absorbance reading. The concentrations of RB19 before and after treatment were recorded using a spectrophotometer (HACH DR 3900) at a maximum wavelength of $595 \mathrm{~nm}$. The adsorptive performance of CTS$\mathrm{GL} / \mathrm{MgO} / \mathrm{Fe}_{3} \mathrm{O}_{4}$ towards RB19 was calculated based on the efficiency of RB19 removal (\%) using the following eq. (2):

$R E \%=\frac{\left(C_{o}-C_{e}\right)}{C_{o}} \times 100$ 
where $C_{o}$ is initial RB19 concentration $(\mathrm{mg} / \mathrm{L})$ and $C_{e}$ is equilibrium RB19 concentration $(\mathrm{mg} / \mathrm{L})$.

\subsection{Batch adsorption experiment}

The adsorptive removal of $\mathrm{RB} 19$ was examined using $\mathrm{CTS}-\mathrm{GL} / \mathrm{MgO} / \mathrm{Fe}_{3} \mathrm{O}_{4}$ as an adsorbent in batch adsorption system. The results of experiments comprised of 4-varibles BBD matrix from Table 2 reveal that the highest RB19 removal (87.5\%) was attained at the experimental run 2. The $\mathrm{BBD}$ matrix run 2 follows this process conditions of $\mathrm{A}$ : CTS-GL/MgO/Fe $3 \mathrm{O}_{4}$ dosage $(0.1 \mathrm{~g}), \mathrm{B}$ : initial solution $\mathrm{pH}(4.0), \mathrm{C}$ : process temperature $\left(45^{\circ} \mathrm{C}\right)$ and $\mathrm{D}$ : contact time (25 min). With these optimized adsorption conditions, the batch adsorption study was carried out. Moreover, the adsorption isotherm and kinetic study were performed under the similar conditions given in run 2 of Table 2, except the parameter range values of initial RB19 concentrations (20-350 mg/L) versus contact time $(0-480 \mathrm{~min})$. The adsorption capacity of the CTS-GL/MgO/Fe $3 \mathrm{O}_{4}$ towards RB19 at equilibrium time was calculated using following eq. (3).

$q_{e}=\frac{\left(C_{o}-C_{e}\right) V}{W}$

where $q_{e}$ is equilibrium adsorption capacity of CTS-GL/MgO/Fe $3 \mathrm{O}_{4}(\mathrm{mg} / \mathrm{g}), V$ is the volume of RB19 solution (L) and $W$ is the applied mass of CTS-GL/MgO/Fe $\mathrm{O}_{4}(\mathrm{~g})$. 
3. Results and discussion

\subsection{Characterization}

The results of the physicochemical characteristics of the CTS-GL/MgO/Fe $3 \mathrm{O}_{4}$ were mentioned in Table 3. The results of analysis of BET surface area of CTS-GL/MgO/Fe $3 \mathrm{O}_{4}$ was found to be $3.70 \mathrm{~m}^{2} / \mathrm{g}$, total pore volume $0.0090 \mathrm{~cm}^{3} / \mathrm{g}$, mean pore volume $0.0004 \mathrm{~cm}^{3} / \mathrm{g}$, and mean pore diameter $9.77 \mathrm{~nm}$. Following IUPAC classification, the mean pore diameter indicates that the CTS-GL/MgO/Fe ${ }_{3} \mathrm{O}_{4}$ is a mesostructured type [35]. This relatively low surface area can be assigned to the interaction exhibited in the interfacial region among $\mathrm{CTS}, \mathrm{MgO}$, and cross-linking agent [36].

Moreover, the actual free amino $\left(-\mathrm{NH}_{2}\right)$ group content in the molecular structure of CTS$\mathrm{GL} / \mathrm{MgO} / \mathrm{Fe}_{3} \mathrm{O}_{4}$ after crosslinking process with GL was determined using potentiometric titrations and the result shows that the adsorbent CTS-GL/MgO/Fe $3 \mathrm{O}_{4}$ has $15.7 \%$ of free amino $\left(-\mathrm{NH}_{2}\right)$ on its surface. The relatively low existence of free amine $\left(-\mathrm{NH}_{2}\right)$ group on the of CTS-GL/MgO/Fe $3 \mathrm{O}_{4}$ reconfirmed the formation of the Schiff's-base system between amino $\left(-\mathrm{NH}_{2}\right)$ functional group of CTS and aldehyde functional groups of GL [20]. In this regard, the available free amino (-NH$)$ group on the surface of CTS-GL/MgO/Fe $3 \mathrm{O}_{4}$ still considered at the preferable level, since the amino $\left(-\mathrm{NH}_{2}\right)$ group offers significant contribution in the adsorptive removal of RB19 through the electrostatic force attraction exhibited between positive charge of protonated amino $\left(-\mathrm{NH}_{3}{ }^{+}\right)$ groups of CTS-GL/MgO/Fe $\mathrm{O}_{4}$ and negative charge of anionic dye (RB19).

The X-ray diffraction analysis was used to examine the phase components and crystalline characteristics of the CTS-GL/MgO/Fe $\mathrm{O}_{4}$. The XRD pattern of the CTS-GL/MgO/ $\mathrm{Fe}_{3} \mathrm{O}_{4}$ is illustrated in Fig. 2. The XRD spectrum shows the diffraction peaks in predominant of magnetite 
phase crystalline spectra. Moreover, the distribution of distinguished peaks in the XRD pattern is mainly due to the magnetite strong peaks overlapping and amorphous CTS structure [37].

The synthesis CTS-GL/MgO/Fe $\mathrm{O}_{4}$ and its interaction with $\mathrm{RB} 19$ were investigated by FT-IR spectral analysis in the wavenumber range of $4000 \mathrm{~cm}^{-1}$ to $500 \mathrm{~cm}^{-1}$. The FT-IR spectral analysis results of CTS-GL/MgO/Fe ${ }_{3} \mathrm{O}_{4}$ and $\mathrm{CTS}-\mathrm{GL} / \mathrm{MgO} / \mathrm{Fe}_{3} \mathrm{O}_{4}$ loaded $\mathrm{RB} 19$ are given in Fig. 3a and Fig. 3b, respectively. The FT-IR spectrum of CTS-GL/MgO/Fe $3 \mathrm{O}_{4}$ exhibits several characteristic peaks at $3300 \mathrm{~cm}^{-1}$ and $3200 \mathrm{~cm}^{-1}$, indicated the stretching vibration of amine or hydroxyl functional group in the CTS-GL/MgO/Fe $\mathrm{O}_{4}$ [38]. A strong absorption peak at $2300 \mathrm{~cm}^{-1}$ can be assigned to the $\mathrm{M}-\mathrm{OH}(\mathrm{M}=\mathrm{Mg}$ and $\mathrm{Fe})$, and signifies the formation of magnetic CTS-based [39]. The peak observed around $1660 \mathrm{~cm}^{-1}$ indicates a stretching vibration due to the presence of $\mathrm{C}=\mathrm{N}$ bond resulted from the cross-linking interactions take place between the functional groups of carbonyls (GL) and amino group of CTS [20]. The CTS-GL/MgO/Fe $3 \mathrm{O}_{4}$ also presents a peak at $1300 \mathrm{~cm}^{-1}(\mathrm{C}-\mathrm{O}-\mathrm{C})$, corresponds to asymmetric stretching vibrations, and a peak at $1030 \mathrm{~cm}^{-1}$, indicates stretching vibrations of $\mathrm{C}-\mathrm{O}$ functional group and these peaks can be assigned to the CTS glycosidic band in CTS-GL/MgO/Fe ${ }_{3} \mathrm{O}_{4}$ biocomposite $[40,41]$. The sharp peak at $699 \mathrm{~cm}^{-1}$ can be attributed to $\mathrm{MgO}$ nanoparticles [26]. The FT-IR spectrum of CTS-GL/MgO/Fe $3 \mathrm{O}_{4}$ loaded with RB19 (Fig. 3b) displays similar profile to spectrum presented in Fig. 3a with slight shift in some peak positions especially at $1500 \mathrm{~cm}^{-1}$ which signifies the existence of the $\mathrm{C}=\mathrm{C}$ functional group of the aromatic ring of RB19 loaded on the CTS-GL/MgO/Fe ${ }_{3} \mathrm{O}_{4}$ surface [42].

The surface examination of the CTS-GL/MgO/Fe $3 \mathrm{O}_{4}$ before and after adsorption of RB19 was visualized using SEM-EDX characterization. The result of SEM-EDX analysis was represented in Fig. 4. The external micro-graphical structure of the CTS-GL/MgO/Fe $3 \mathrm{O}_{4}$ (Fig. 4a) shows irregular, heterogonous, wavy structure, and with different sizes of pores and cavities are 
well distributed on the $\mathrm{GL} / \mathrm{MgO} / \mathrm{Fe}_{3} \mathrm{O}_{4}$ surface. This surface characteristic offers an ideal morphology for effective capturing of RB19 dye molecules with high possibility of efficient penetration towards inner adsorption active sites. The EDX spectrum of the CTS-GL/MgO/Fe $\mathrm{O}_{4}$ shows the presence of various elements such as $\mathrm{C}, \mathrm{O}, \mathrm{Fe}, \mathrm{N}, \mathrm{Mg}$, and $\mathrm{Zr}$. The presence of $\mathrm{N}$ element in the biocomposite contributes to amine group of CTS, and $\mathrm{Fe}$ signifies the magnetic $\mathrm{Fe}_{3} \mathrm{O}_{4}$. On the other hand, Fig. 4b displays the SEM and EDX results of CTS-GL/MgO/Fe $3 \mathrm{O}_{4}$ biocomposite after adsorption of RB19. The SEM image shows the conversion of the morphological surface to be more compact and less porous than the SEM image in Fig 4a. This observation can be mainly assigned to the adsorption of RB19 onto the surface of CTS-GL/MgO/Fe $\mathrm{O}_{4}$. This observation was reconfirmed by EDX analysis (Fig 4b) which indicates the detection of S atom that belongs to the RB19 adsorbed onto the CTS-GL/MgO/Fe $3 \mathrm{O}_{4}$ surface.

\subsection{BBD model fitting}

Statistical analysis and determination of the significant effect of the adsorption independent variables and their interactions for the RB19 removal data were accomplished by analysis of variance (ANOVA). The statistical results derived from the ANOVA of the RB19 removal are listed in Table 4. A model F-value of 50.75 (p-value <0.0001) signifies that the RB19 removal model is significant from a statistical stand point [43]. The value of the correlation coefficient $\left(R^{2}\right)$ for the RB19 removal model was 0.98 , which implies the accuracy of the fitting of the RB19 removal model, and the strong correlation between the expected and experimental RB19 removal values [44]. From a statistical point of view, model codes are considered significant terms when

the $\mathrm{P}$-value is less than 0.05. As a result, $\mathrm{A}, \mathrm{B}, \mathrm{D}, \mathrm{AB}, \mathrm{AC}, \mathrm{AD}, \mathrm{BC}, \mathrm{BD}, \mathrm{B}^{2}, \mathrm{C}^{2}$, and $\mathrm{D}^{2}$ are 
important terms in the process of removing RB19. Eq. 4 shows the quadratic polynomial model used to correlate the experimental relationship between RB19 removal and the examined variables.

$\mathrm{RB} 19$ removal $(\%)=+42.90+19.36 \mathrm{~A}-10.61 \mathrm{~B}+3.80 \mathrm{D}-5.97 \mathrm{AB}+3.52 \mathrm{AC}+3.58 \mathrm{AD}+$ $6.13 \mathrm{BC}-6.52 \mathrm{BD}+7.18 \mathrm{~B}^{2}+4.35 \mathrm{C}^{2}+5.07 \mathrm{D}^{2}$

In addition to the above, verification of the experimental data can be accomplished by analyzing the drawings extracted from the BBD model, such as the actual versus the expected, and the normal probability of the residuals. The predicted versus actual plot of RB19 removal (\%) is depicted in Fig. 5a. As per Fig. 5a, the actual points were mostly close to the expected points, indicating that the BBD model can adequately optimize the RB19 dye adsorption process. The normal probability plot of residuals is demonstrated in Fig. 5b. The independence of the residuals can be inferred from Fig. 5b, where the normal distribution of all points around the straight line [45]. Another statistical validation was made by Cook's distance as shown in Fig. 5c. In general, the acceptable Cook's distance should be less than 1. As presented in Fig. 5 c, all observed values are less than 1. Moreover, 27 runs out 29 runs are even below 0.2, and in some cases equal to zero which indicates the significant effect on the predictive power of the model.

\subsection{Surface plot for responses}

The explanation of the interaction effects of two operational variables on RB19 removal (\%) can be obtained from ANOVA results and can be graphically presented in three-dimensional (3D) response surfaces. ANOVA results (Table 4) indicate the existence of five significant interactions between the adsorption individual variables as follows: $\mathrm{AB}($ dose $\times \mathrm{pH}), \mathrm{AC}(\mathrm{dose} \times$ temperature), $\mathrm{BC}(\mathrm{pH} \times$ temperature), $\mathrm{AD}$ (dose $\times$ time $)$, and $\mathrm{BD}(\mathrm{pH} \times$ time $)$. Thus, Fig. 6a exhibits the 3D surface plot of the significant interaction between $\mathrm{AB}($ dose $\times \mathrm{pH})$ on the $\mathrm{RB} 19$ removal 
(\%), while other operational variables were kept constant (temperature $=45^{\circ} \mathrm{C}$ and time $=25 \min$ ). From Fig. 6a, it was observed that the RB19 removal (\%) was gradually increased by decreasing the solution $\mathrm{pH}$ towards acidic environment $(\mathrm{pH}=4)$. This observation can be explained by referring to the net surface charge of CTS-GL/MgO/Fe ${ }_{3} \mathrm{O}_{4}$ which determines from $\mathrm{pH}_{\mathrm{pzc}}$ test as presented in Fig. 6b. The results indicates that the $\mathrm{pH}_{\mathrm{pzc}}$ value for CTS-GL/MgO/Fe $3 \mathrm{O}_{4}$ is 9.0 , and the surface of the CTS-GL/MgO/Fe ${ }_{3} \mathrm{O}_{4}$ will acquire a negative charge when solution $\mathrm{pH}$ above 9.0, and positive charge when solution $\mathrm{pH}$ below 9.0. According to this fact, the surface of CTS$\mathrm{GL} / \mathrm{MgO} / \mathrm{Fe}_{3} \mathrm{O}_{4}$ will acquire positive charge due to the protonation of amino $\left(-\mathrm{NH}_{3}{ }^{+}\right)$by access of proton $\left(\mathrm{H}^{+}\right)$in the treated solution. Consequently, an electrostatic attraction can be found between the cationic functional group on the surface of the CTS-GL/MgO/Fe $3 \mathrm{O}_{4}$ and the RB19 dye as exhibited in Eq. (5).

$$
\mathrm{CTS}-\mathrm{GL} / \mathrm{MgO} / \mathrm{Fe}_{3} \mathrm{O}_{4}{ }^{+}+\mathrm{RB} 19^{-} \leftrightarrow \mathrm{CTS}-\mathrm{GL} / \mathrm{MgO} / \mathrm{Fe}_{3} \mathrm{O}_{4}{ }^{+}{ }^{-}{ }^{-} \mathrm{RB} 19
$$

Other statistically significant interactions were observed between AC (dose $\times$ temperature) and $\mathrm{BC}(\mathrm{pH} \times$ temperature) as presented in 3D surface plot in Fig. 6c and Fig. 6d, respectively. Noteworthy, the other operational parameters were kept constant as follows: AC interaction ( $\mathrm{pH}$ $=7$ and time $=25 \mathrm{~min})$ and $\mathrm{BC}$ interaction $($ dose $=0.06 \mathrm{~g}$ and time $=25 \mathrm{~min})$. As can be seen from Fig. 6c and Fig. 6d, the RB19 removal (\%) did not show any remarkable change or even slightly decreased by increasing the working temperature up to $60{ }^{\circ} \mathrm{C}$, which may indicate that the adsorption process of RB19 onto the surface of the CTS-GL/MgO/Fe $3 \mathrm{O}_{4}$ is an exothermic in nature [46]. 
Furthermore, other statistically significant interactions were observed between AD (dose $\times$ time), and $\mathrm{BD}(\mathrm{pH} \times$ time $)$ as presented in 3D surface plot in Fig. 6e and Fig. 6f, respectively. Noteworthy, the other operational parameters were kept constant as follows: $\mathrm{AD}$ interaction $(\mathrm{pH}$ $=7$ and temperature $=45^{\circ} \mathrm{C}$ ) and $\mathrm{BD}$ interaction (dose $=0.06 \mathrm{~g}$ and temperature $=45^{\circ} \mathrm{C}$ ). Regarding the adsorbent dose, the result obtained from Fig. 6e elucidates that the RB19 removal (\%) increased by increasing the dose of the CTS-GL/ZnO/Fe $\mathrm{O}_{4}$. This observation can be assigned to more active adsorption sites will be available in the bulk dye solution by loading more amounts of the adsorbent (CTS-GL/ZnO/Fe $3 \mathrm{O}_{4}$ ), and the greater number of active adsorption sites will lead to more contribution for RB19 dye capturing [47]. Regarding the contact time (Fig. 6f), the RB19 removal (\%) increased rapidly by extending the contact time from $10 \mathrm{~min}$ to $40 \mathrm{~min}$, more contact time will offer sufficient time to the RB19 dye molecules to penetrate further inside the molecular structure of the CTS-GL/ZnO/Fe $\mathrm{O}_{4}$, and to efficiently reach the inner active adsorption.

\subsection{Adsorption study}

The adsorption experiments were carried out by varying the contact time (0-180 min) of the adsorption process and the initial concentration of RB19 (20-350 mg/L). The experimental data of varying contact time were fitted to the adsorption kinetic and isotherm models. The other adsorption process parameters of CTS-GL/MgO/ $\mathrm{Fe}_{3} \mathrm{O}_{4}$ dosage (0.1), initial solution $\mathrm{pH}$ (4.0), and process temperature $\left(45^{\circ} \mathrm{C}\right)$ were kept constant according to the BBD based optimal conditions. The results of effect of contact time and initial RB19 concentrations are represented in Fig. 7a. The results clearly indicate that the adsorption capacity of CTS-GL/MgO/Fe $3 \mathrm{O}_{4}$ towards $\mathrm{RB} 19$ uptake for all studied initial RB19 concentrations presented a sharp increase followed by the attainment of a plateau. The increase in the adsorption capacity of CTS-GL/MgO/Fe $\mathrm{O}_{3}$ with the 
increase of the initial RB 19 concentration was mainly due to the increase in the driving force for the transferring of RB 19 dye molecules from aqueous solution to the CTS-GL/MgO/Fe $\mathrm{F}_{3}$ surface [48].

\subsection{Adsorption kinetic}

The curves of the adsorption process of varying contact time versus different initial RB 19 concentrations are presented in Fig. 7a. It is clear from the results that the adsorption capacity of CTS-GL/MgO/Fe $3 \mathrm{O}_{4}$ towards RB19 uptake was rapidly increased during the initial contact time of the adsorption process, further followed with same adsorption capacity irrespective of the increase of the contact time and signifies the state of equilibrium attainment for all dye concentrations. The expressions of pseudo-first order (PFO) [49], and pseudo-second order (PSO) [50], kinetic model are given in the Eqs. (6) and (7), respectively:

$q_{t}=q_{e}\left(1-\exp ^{-k_{1} t}\right)$

$q_{t}=\frac{q_{e}^{2} k_{2} t}{1+q_{e} k_{2} t}$

where $q_{e}(\mathrm{mg} / \mathrm{g})$ and $q_{t}(\mathrm{mg} / \mathrm{g})$ are the adsorption capacity of CTS-GL/MgO/Fe $3 \mathrm{O}_{4}$ biocomposite $(\mathrm{mg} / \mathrm{g})$ at the equilibrium and at time $t(\mathrm{~min}) \cdot k_{1}(1 / \mathrm{min})$ and $k_{2}(\mathrm{~g} /(\mathrm{mg} \cdot \mathrm{min}))$ are the pseudo-first order rate constant and pseudo-second order rate constant, respectively. The results of kinetic model parameters of the pseudo-first order rate constant and pseudo-second order rate constant models along with their values of coefficient of determination $\left(R^{2}\right)$ are presented in Table 5 . The kinetic model results reveal that the RB19 adsorption using CTS-GL/MgO/Fe $3 \mathrm{O}_{4}$ in a good agreement with the pseudo-second order kinetic model with higher $R^{2}$ values for all the initial 
RB19 concentrations compared to pseudo-first order kinetic models $R^{2}$ values. The best fit of experimental data to the pseudo-second-order kinetic model indicated that the chemisorption was the main step of controlling the interaction between CTS-GL/MgO/Fe $3 \mathrm{O}_{4}$ and $\mathrm{RB} 19$ [51].

\subsection{Adsorption isotherm}

The result of the adsorption isotherm analysis of RB19 is shown in Fig. 7b. The equilibrium data of the adsorption experiments were determined at initial RB19 concentrations of $20 \mathrm{mg} / \mathrm{L}$, $50 \mathrm{mg} / \mathrm{L}, 100 \mathrm{mg} / \mathrm{L}, 150 \mathrm{mg} / \mathrm{L}, 200 \mathrm{mg} / \mathrm{L}, 250 \mathrm{mg} / \mathrm{L}$, and $350 \mathrm{mg} / \mathrm{L}$, and at the process temperature of $45^{\circ} \mathrm{C}$. The adsorption equilibrium data were examined by three isotherm models of Langmuir [52], Freundlich [53], and Temkin [54]. The non-linear expression of the Langmuir, Freundlich and Temkin models are mentioned in the Eqs. (8), (9) and (10), respectively:

$q_{e}=\frac{q_{\max } K_{a} C_{e}}{1+K_{a} C_{e}}$

where $q_{\max }(\mathrm{mg} / \mathrm{g})$ represents the maximum monolayer adsorption capacity and $\mathrm{K}_{\mathrm{a}}(\mathrm{L} / \mathrm{mg})$ refers to the Langmuir constant.

$q_{e}=K_{f} C_{e}^{1 / n}$

where $K_{F}(\mathrm{mg} / \mathrm{g})$ Freundlich constant represent adsorption capacity and $n_{F}(\mathrm{~L} / \mathrm{mg})$ is the Freundlich constant indicates adsorption intensity.

$$
q_{e}=\frac{R T}{b_{T}} \ln \left(K_{T} C_{e}\right)
$$

where $K_{T}(\mathrm{~L} / \mathrm{mg})$ is the Temkin constant, $R(8.314 \mathrm{~J} / \mathrm{mol} \mathrm{K})$ is the universal gas constant, $T(\mathrm{~K})$ is the absolute temperature, and $b_{T}(\mathrm{~J} / \mathrm{mol})$ indicates the heat of adsorption. The best fit of the 
adsorption equilibrium data inferred from the values of $R^{2}$ values listed in Table 6 . The order of best fit of equilibrium data to isotherm models: Freundlich $>$ Langmuir $>$ Temkin. The results confirmed the unequal affinity of $\mathrm{RB} 19$ by the CTS-GL/MgO/Fe $3 \mathrm{O}_{4}$ and presented the heterogeneous nature and multilayer adsorption process [55]. The maximum monolayer adsorption capacity recorded according to the Langmuir isotherm model was $193.2 \mathrm{mg} / \mathrm{g}$, which is observed as the higher adsorption capacity compared to the other adsorbents reported in the literature (Table 7).

\subsection{Adsorption mechanism}

The acid dye (RB19) adsorption mechanism was proposed according to the available functional groups on the CTS-GL/MgO/Fe ${ }_{3} \mathrm{O}_{4}$ surface, as given in Fig. 8. CTS-GL/MgO/Fe $\mathrm{O}_{4}$ is distinguished by the availability of different active groups that can play an essential role in the adsorption process of RB19 dye. Among these groups, protonated amino $\left(-\mathrm{NH}_{3}{ }^{+}\right)$group, $\left(-\mathrm{OH}_{2}{ }^{+}\right)$, and $\mathrm{Mg}(\mathrm{OH})^{+}$resulted from $\mathrm{MgO}$ nanoparticles. These functional groups with positive charge can efficiently attract the negative charge $\left(-\mathrm{SO}_{3}{ }^{-}\right)$groups of the $\mathrm{RB} 19$ dye. The hydrogen bonding interactions can be formed via the interaction of CTS-GL/MgO/Fe ${ }_{3} \mathrm{O}_{4}$ 's hydrogens with nitrogen and oxygen atoms of RB19 dye. Moreover, another interaction can be generated from the interaction between the electron donor groups in $\mathrm{CTS}-\mathrm{GL} / \mathrm{MgO} / \mathrm{Fe}_{3} \mathrm{O}_{4}$ with the electron acceptor system in RB19 dye [20]. Finally, the interactions of the hydrogen of the hydroxyl groups with the aromatic system of the RB19 dye leads to interactions known as Yoshida H-bonding [44]. 


\section{Conclusions}

A novel magnetic crosslinked chitosan-glutaraldehyde/ $\mathrm{MgO} / \mathrm{Fe}_{3} \mathrm{O}_{4} \quad$ (CTS$\mathrm{GL} / \mathrm{MgO} / \mathrm{Fe}_{3} \mathrm{O}_{4}$ ) biocomposite adsorbent was successfully made and applied for the capturing of Reactive Blue19 (RB19) synthetic textile dye from aqueous solution. The best RB19 removal conditions were found at $\mathrm{CTS}-\mathrm{GL} / \mathrm{MgO} / \mathrm{Fe}_{3} \mathrm{O}_{4}$ dosage $(0.1 \mathrm{~g})$, initial solution $\mathrm{pH}$ (4.0), process temperature $\left(45^{\circ} \mathrm{C}\right)$, and contact time $(25 \mathrm{~min})$ as investigated by BBD. The isotherm model of Freundlich best described the equilibrium data revealed heterogeneous and multilayer adsorption. The maximum adsorption capacity of CTS-GL/MgO/Fe $3 \mathrm{O}_{4}$ biocomposite towards $\mathrm{RB} 19$ was predicted according to Langmuir isotherm model was $193.2 \mathrm{mg} / \mathrm{g}$. The experimental data of the kinetic models revealed that the RB 19 adsorption is governed by the chemisorption process. Several interactions are contributed to the mechanics of RB19 adsorption by CTS-GL/MgO/Fe ${ }_{3} \mathrm{O}_{4}$ such as electrostatic attraction, H-bonding, $n-\pi$, and Yoshida H-bonding. This study signifies the ability of $\mathrm{CTS}-\mathrm{GL} / \mathrm{MgO} / \mathrm{Fe}_{3} \mathrm{O}_{4}$ to be an effective magnetic adsorbent for treating wastewater containing organic dyes.

\section{Acknowledgments}

The authors would like to thank the Faculty of Applied Sciences, Universiti Teknologi MARA, Shah Alam for all facilities. The authors would like to thank Mrs. Nurfarah Farini Binti Muhamad Kamarazzaman, Penolong Pegawai Sains (Assistant Science Officer) at Applied 
Sciences, Universiti Teknologi MARA, Shah Alam for facilitating XRD analysis. Zeid A. ALOthman is grateful to the Researchers Supporting Project No. (RSP-2021/1), King Saud University, Riyadh, Saudia Arabia.

\section{References}

[1] A.H. Jawad, A. S. Abdulhameed, L. D. Wilson, M. A. K. M. Hanafah, W. I. Nawawi, Z. A. ALOthman, M. R. Khan, Fabrication of Schif's base chitosan-glutaraldehyde/activated charcoal composite for cationic dye removal: Optimization using response surface methodology, J. Polym. Environ. 29 (2021) 2855-2868.

[2] A. Tkaczyk, K. Mitrowska, A. Posyniak, Synthetic organic dyes as contaminants of the aquatic environment and their implications for ecosystems: A review. Sci. Total Environ. 717 (2020) 137222 .

[3] G. Sriram, M. Kigga, U.T. Uthappa, R.M. Rego, V. Thendral, T. Kumeria, M.D. Kurkuri, Naturally available diatomite and their surface modification for the removal of hazardous dye and metal ions: A review. Adv. Colloid Interface Sci. 282 (2020) 102198.

[4] F. Ali, N. Ali, I. Bibi, A. Said, S. Nawaz, Z. Ali, M. Bilal, Adsorption isotherm, kinetics and thermodynamic of acid blue and basic blue dyes onto activated charcoal. Case Stud. Chem. Environ. Eng. 2 (2020) 100040.

[5] T. Rasheed, F. Nabeel, M. Bilal, H.M. Iqbal, Biogenic synthesis and characterization of cobalt oxide nanoparticles for catalytic reduction of direct yellow-142 and methyl orange dyes, Biocatal. Agric. Biotechnol. 19 (2019) 101154.

[6] S. Benkhaya, S. M'rabet, A. El Harfi, Classifications, properties, recent synthesis and applications of azo dyes. Heliyon 6(1) (2020) e03271.

[7] Y. Li, Z. Li, Y. Xia, H. Li, J. Shi, A. Zhang, L. Gao, Fabrication of ternary AgBr/BiPO $/$ g$\mathrm{C}_{3} \mathrm{~N}_{4}$ heterostructure with dual Z-scheme and its visible light photocatalytic activity for Reactive Blue 19, Environ. Res. 192 (2020) 110260.

[8] C. Ao, J. Zhao, Q. Li, J. Zhang, B. Huang, Q. Wang, C. Lu, Biodegradable all-cellulose composite membranes for simultaneous oil/water separation and dye removal from water, Carbohydra. Polym. 250 (2020) 116872.

[9] C. Cojocaru, L. Clima, Polymer assisted ultrafiltration of AO7 anionic dye from aqueous solutions: Experimental design, multivariate optimization, and molecular docking insights, J. Membr. Sci. 604 (2020) 118054. 
[10] Q. Feng, B. Gao, Q. Yue, K. Guo, Flocculation performance of papermaking sludge-based flocculants in different dye wastewater treatment: Comparison with commercial lignin and coagulants, Chemosphere 262 (2020) 128416.

[11] S. Varjani, P. Rakholiya, H.Y. Ng, S. You, J.A. Teixeira, Microbial degradation of dyes: An overview, Bioresour. Technol. 314 (2020) 123728.

[12] Y. Ghaffari, N.K. Gupta, J. Bae, K.S. Kim, One-step fabrication of $\mathrm{Fe}_{2} \mathrm{O}_{3} / \mathrm{Mn}_{2} \mathrm{O}_{3}$ nanocomposite for rapid photodegradation of organic dyes at neutral pH. J. Mol. Liq. 315 (2020) 113691.

[13] A.H. Jawad, A.S. Abdulhameed, A. Reghioua, Z.M. Yaseen, Zwitterion composite chitosanepichlorohydrin/zeolite for adsorption of methylene blue and reactive red 120 dyes, Int. J. Biol. Macromol. 163 (2020) 756-765.

[14] S.N. Surip, A.S. Abdulhameed, Z.N. Garba, S.S.A. Syed-Hassan, K. Ismail, A.H. Jawad, $\mathrm{H}_{2} \mathrm{SO}_{4}$-treated Malaysian low rank coal for methylene blue dye decolourization and cod reduction: Optimization of adsorption and mechanism study, Surf. Interface. 21 (2020) 100641.

[15] U. Upadhyay, I. Sreedhar, S.A. Singh, C.M. Patel, K.L. Anitha, Recent advances in heavy metal removal by chitosan based adsorbents, Carbohydra. Polym. 251 (2020) 117000.

[16] C. Liu, R. Bai, Recent advances in chitosan and its derivatives as adsorbents for removal of pollutants from water and wastewater, Curr. Opin. Chem. Eng. 4, (2014) 62-70.

[17] A.H. Jawad, A.S. Abdulhameed, N.N.A. Malek, Z.A. ALOthman, Statistical optimization and modeling for color removal and COD reduction of reactive blue 19 dye by mesoporous chitosanepichlorohydrin/kaolin clay composite, Int. J. Biol. Macromol. 164 (2020) 4218-4230.

[18] I.O. Saheed, O.W. Da, F.B.M. Suah, (2020) Chitosan Modifications for Adsorption of Pollutants-A review. J. Hazard. Mater. https://doi.org/10.1016/j.jhazmat.2020.124889

[19] K. Gul, S. Sohni, M. Waqar, F. Ahmad, N.N. Norulaini, M.O. AK, Functionalization of magnetic chitosan with graphene oxide for removal of cationic and anionic dyes from aqueous solution. Carbohydra. Polym. 152 (2016) 520-531.

[20] A.H. Jawad, N.S.A. Mubarak, A.S. Abdulhameed, Tunable Schiff's base-cross-linked chitosan composite for the removal of reactive red 120 dye: Adsorption and mechanism study, Int. J. Biol. Macromol. 142 (2020) 732-741.

[21] M. Vakili, A. Mojiri, H.M. Zwain, J. Yuan, A.S. Giwa, W. Wang, G. Yu, Effect of beading parameters on cross-linked chitosan adsorptive properties, React. Funct. Polym. 144 (2019) 104354. 
[22] A.H. Jawad, N.S.A. Mubarak, A.S. Abdulhameed, Hybrid Crosslinked ChitosanEpichlorohydrin $/ \mathrm{TiO}_{2}$ Nanocomposite for Reactive Red 120 Dye Adsorption: Kinetic, Isotherm, Thermodynamic, and Mechanism Study, J. Polym. Environ. 28 (2020) 624-637.

[23] S.A. Nouh, B.O. Alsobhi, A. Abou Elfadl, K. Benthami, K.D. Khalil, S.M. Riyadh, Structure and thermal investigation of the effect of laser radiation in Chitosan-MgO nanocomposite film. Radiat. Eff. Defects Solids 175(5-6) (2020) 422-432.

[24] N.K. Nga, N.T.T. Chau, P.H. Viet, Preparation and characterization of a chitosan/MgO composite for the effective removal of reactive blue 19 dye from aqueous solution. Journal of Science: Adv. Mater. Dev. 201-202 (2020) 68-93.

[25] Y. Haldorai, J.J. Shim, An efficient removal of methyl orange dye from aqueous solution by adsorption onto chitosan/MgO composite: A novel reusable adsorbent, Appl. Surf. Sci. 292 (2014) 447-453.

[26] Y. Wang, C. Cen, J. Chen, L. Fu, MgO/carboxymethyl chitosan nanocomposite improves thermal stability, waterproof and antibacterial performance for food packaging, Carbohydra. Polym. 236 (2020) 116078.

[27] Y.Z. Huang, Y. Ji, R., Z.W. Kang, F. Li, S.F. Ge, D.P. Yang, X.Q. Fan, Integrating Eggshellderived $\mathrm{CaCO}_{3} / \mathrm{MgO}$ Nanocomposites and Chitosan into a Biomimetic Scaffold for Bone Regeneration, Chem. Eng. J. 395 (2020) 125098.

[28] C.S. Sundaram, N. Viswanathan, S. Meenakshi, Defluoridation of water using magnesia/chitosan composite, J. Hazard. Mater. 163(2-3) (2009) 618-624.

[29] M.K. Patel, M.A. Ali, M. Zafaryab, V.V. Agrawal, M.M.A. Rizvi, Z.A. Ansari, B.D. Malhotra, Biocompatible nanostructured magnesium oxide-chitosan platform for genosensing application, Biosens. Bioelectron. 45 (2013) 181-188.

[30] S.M. Riyadh, K.D. Khalil, A. Aljuhani, Chitosan-MgO Nanocomposite: One Pot Preparation and Its Utility as an Ecofriendly Biocatalyst in the Synthesis of Thiazoles and $[1,3,4]$ thiadiazoles, Nanomater. 8(11) (2018) 928.

[31] D.H.K. Reddy, S.M. Lee, Application of magnetic chitosan composites for the removal of toxic metal and dyes from aqueous solutions. Adv. Colloid Interface sci. 201 (2013) 68-93.

[32] A. Dalvand, R. Nabizadeh, M.R. Ganjali, M. Khoobi, S. Nazmara, A.H. Mahvi, Modeling of Reactive Blue 19 azo dye removal from colored textile wastewater using L-arginine-functionalized $\mathrm{Fe} 3 \mathrm{O} 4$ nanoparticles: Optimization, reusability, kinetic and equilibrium studies, J. Magn. Magn. Mater. 404 (2016) 179-189.

[33] R.S. Vieira, M.M. Beppu, Interaction of natural and crosslinked chitosan membranes with Hg (II) ions, Colloids Surf. A Physicochem. Eng. Asp. 279 (1-3) (2006) 196-207. 
[34] Y.Y. Hu, C. Pan, X. Zheng, F. Hu, L. Xu, G. Xu, X. Peng, Prediction and optimization of adsorption properties for $\mathrm{Cs}+$ on $\mathrm{NiSiO} @ \mathrm{NiAlFe}$ LDHs hollow spheres from aqueous solution: Kinetics, isotherms, and BBD model, J. Hazard. Mater. 401 (2020) 123374.

[35] K.S. Sing, Reporting physisorption data for gas/solid systems with special reference to the determination of surface area and porosity (Recommendations 1984), Pure Appl. Chem. 57 (4) (1985) 603-619.

[36] L. Chen, P. Wu, M. Chen, X. Lai, Z. Ahmed, N. Zhu, T. Liu, Preparation and characterization of the eco-friendly chitosan/vermiculite biocomposite with excellent removal capacity for cadmium and lead, Appl. Clay Sci. 159 (2018) 74-82.

[37] J.M. dos Santos, C.R. Pereira, L.A.A. Pinto, T. Frantz, É.C. Lima, E.L. Foletto, G.L. Dotto, Synthesis of a novel $\mathrm{CoFe}_{2} \mathrm{O}_{4} /$ chitosan magnetic composite for fast adsorption of indigotine blue dye. Carbohydra. Polym. 217 (2019) 6-14.

[38] Y. Yang, N. Ali, A. Khan, S. Khan, S. Khan, H. Khan, M. Bilal, Chitosan-capped ternary metal selenide nanocatalysts for efficient degradation of carcinogenic Congo red dye in sunlight irradiation, Int. J. Biol. Macromol. 167 (2020) 169-181.

[39] J. Jaafari, H. Barzanouni, S. Mazloomi, N.A.A. Farahani, K. Sharafi, P. Soleimani, G.A. Haghighat, Effective adsorptive removal of reactive dyes by magnetic chitosan nanoparticles: Kinetic, isothermal studies and response surface methodology, Int. J. Boil. Macromol. 164 (2020) 344-355.

[40] N. Naeeji, Y. Shahbazi, N. Shavisi, Effect of gamma irradiation on physico-mechanical and structural properties of basil seed mucilage-chitosan films containing Ziziphora clinopodioides essential oil and $\mathrm{MgO}$ nanoparticles for rainbow trout packaging, J. Food Process. Preserv. 44(10) (2020) e14781.

[41] M.B.B. Pereira, D.B. França, R.C. Araújo, E.C. Silva Filho, B. Rigaud, M.G. Fonseca, M. Jaber, Amino hydroxyapatite/chitosan hybrids reticulated with glutaraldehyde at different $\mathrm{pH}$ values and their use for diclofenac removal, Carbohydra. Polym. 236 (2020) 116036.

[42] A.H. Jawad, A.S. Abdulhameed, Facile synthesis of crosslinked chitosantripolyphosphate/kaolin clay composite for decolourization and COD reduction of remazol brilliant blue R dye: Optimization by using response surface methodology, Colloids Surf. A Physicochem. Eng. Asp. 605 (2020) 125329.

[43] A.H. Jawad, A.S. Abdulhameed, Statistical modeling of methylene blue dye adsorption by high surface area mesoporous activated carbon from bamboo chip using $\mathrm{KOH}$-assisted thermal activation, Energy Ecol. Environ. 5(6) (2020) 456-469.

[44] A.S. Abdulhameed, A.T. Mohammad, A.H. Jawad, Application of response surface methodology for enhanced synthesis of chitosan tripolyphosphate/ $\mathrm{TiO}_{2}$ nanocomposite and adsorption of reactive orange 16 dye, J. Clean. Prod. 232 (2019) 43-56. 
[45] A.H. Jawad, N.N.A. Malek, A.S. Abdulhameed, R. Razuan, Synthesis of Magnetic ChitosanFly Ash/Fe3O4 Composite for Adsorption of Reactive Orange 16 Dye: Optimization by BoxBehnken Design, J. Polym. Environ. 28(3) (2020) 1068-1082.

[46] A. Kausar, F. Sher, A. Hazafa, A. Javed, M. Sillanpää, M. Iqbal, Biocomposite of sodiumalginate with acidified clay for wastewater treatment: Kinetic, equilibrium and thermodynamic studies, Int. J. Biol. Macromol. 161 (2020) 1272-1285.

[47] E.M. Kalhori, T.J. Al-Musawi, E. Ghahramani, H. Kazemian, M. Zarrabi, Enhancement of the adsorption capacity of the light-weight expanded clay aggregate surface for the metronidazole antibiotic by coating with $\mathrm{MgO}$ nanoparticles: studies on the kinetic, isotherm, and effects of environmental parameters, Chemosphere, 175 (2017) 8-20.

[48] V.O. Njoku, M.A. Islam, M. Asif, B.H. Hameed, Preparation of mesoporous activated carbon from coconut frond for the adsorption of carbofuran insecticide, $\mathrm{J}$.

Anal. Appl. Pyrol. 110 (2014) 172-180.

[49] S. Lagergren, Zur theorie der sogenannten adsorption geloster stoffe, Vet.Akad.Handl. 24 (1898) 1-39.

[50] Y. S. Ho, G. McKay, Sorption of dye from aqueous solution by peat, Chem. Eng. J. 70 (1998) 115-124.

[51] L. Huang, Z. Yang, D. Lei, F. Liu, Y. He, H. Wang, J. Luo, Experimental and modeling studies for adsorbing different species of fluoride using lanthanum-aluminum perovskite, Chemosphere, 263 (2020)128089.

[52] I. Langmuir, The adsorption of gases on plane surfaces of glass, mica and platinum, J. Am. Chem. Soc. 40 (1918) 1361-1403.

[53] H.M.F. Frenudlich, Over the adsorption in solution, J. Phys. Chem. 57 (1906) 385-471.

[54] M. I. Temkin, Kinetics of ammonia synthesis on promoted iron catalysts, Acta physiochim. URSS. 12 (1940) 327-356.

[55] J. Chen, H. Hu, J. Yang, H. Xue, Y. Tian, K. Fan, Y. Liu, Removal behaviors and mechanisms for series of azo dye wastewater by novel nano constructed macro-architectures material, Bioresour. Technol. 322 (2020) 124556.

[56] K. Vijayaraghavan, S.W. Won, Y.S. Yun, Treatment of complex Remazol dye effluent using sawdust-and coal-based activated carbons, J. Hazard. Mater. 167 (1-3) (2009) 790-796.

[57] V. Janaki, B.T. Oh, K. Shanthi, K.J. Lee, A.K. Ramasamy, S. Kamala-Kannan, Polyaniline/chitosan composite: an eco-friendly polymer for enhanced removal of dyes from aqueous solution, Synth. Met. 162 (11-12) (2012) 974-980. 
[58] D.N. Phan, R.A. Rebia, Y. Saito, D. Kharaghani, M. Khatri, T. Tanaka, I.S. Kim, Zinc oxide nanoparticles attached to polyacrylonitrile nanofibers with hinokitiol as gluing agent for synergistic antibacterial activities and effective dye removal, J. Ind. Eng. Chem. 85 (2020) 258268.

[59] V. Nair, A. Panigrahy, R. Vinu, Development of novel chitosan-lignin composites for adsorption of dyes and metal ions from wastewater, Chem. Eng. J. 254 (2014) 491-502.

[60] M. Abbasi, Synthesis and characterization of magnetic nanocomposite of chitosan/ $\mathrm{SiO}_{2} /$ carbon nanotubes and its application for dyes removal, J. Clean. Prod. 145 (2017) 105-113.

[61] K. Chinoune, K. Bentaleb, Z. Bouberka, A. Nadim, U. Maschke, Adsorption of reactive dyes from aqueous solution by dirty bentonite, Appl. Clay Sci. 123 (2016) 64-75.

[62] M.M. Silva, M.M. Oliveira, M.C. Avelino, M.G. Fonseca, R.K. Almeida, E.C. Silva Filho, Adsorption of an industrial anionic dye by modified-KSF-montmorillonite: evaluation of the kinetic, thermodynamic and equilibrium data, Chem. Eng. J. 203 (2012) 259-268.

[63] C.J. Mate, S. Mishra, Synthesis of borax cross-linked Jhingan gum hydrogel for remediation of Remazol Brilliant Blue R (RBBR) dye from water: adsorption isotherm, kinetic, thermodynamic and biodegradation studies, Int. J. Biol. Macromol. 151 (2020) 677-690. 
Figures

$\underbrace{\mathrm{CTS}}_{\mathrm{OH}}>_{\mathrm{NH}_{2}}^{\mathrm{OH}}$

Chitosan (CTS)

$$
+
$$

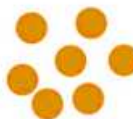

Magnesium oxide (MgO) nanoparticles

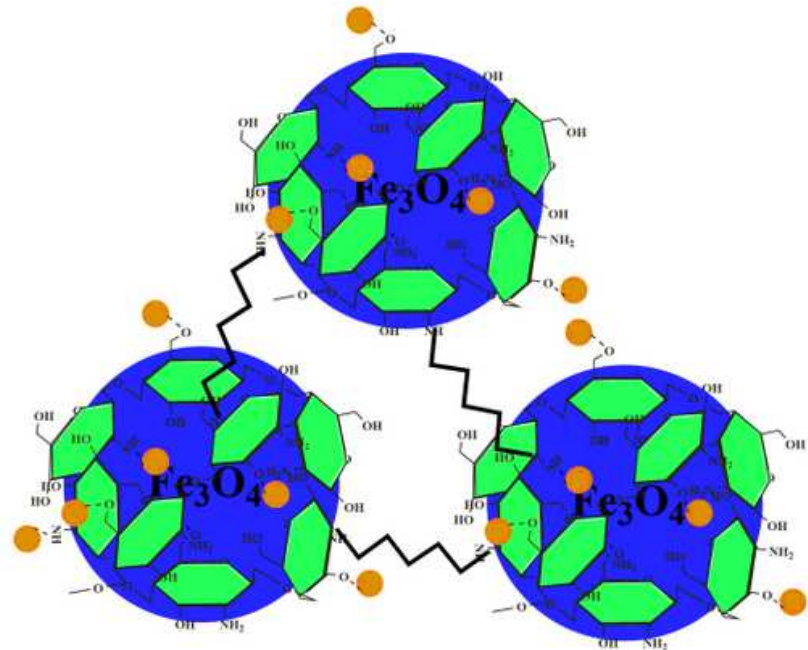

Magnetic chitosan-glutaraldehyde $/ \mathrm{MgO} / \mathrm{Fe}_{3} \mathrm{O}_{4}$ beads (CTS-GL/MgO/ $/ \mathrm{Fe}_{3} \mathrm{O}_{4}$ )

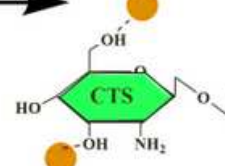

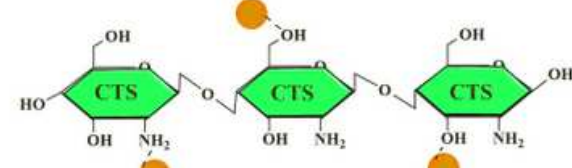

$\left(\mathrm{Fe}^{3+}, \mathrm{Fe}^{+2}\right)$
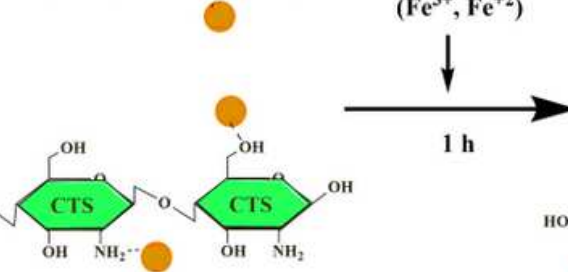

$1 \mathrm{~h}$

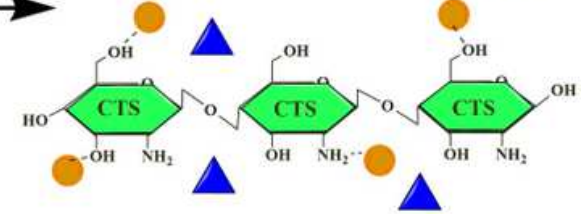

CTS-MgO
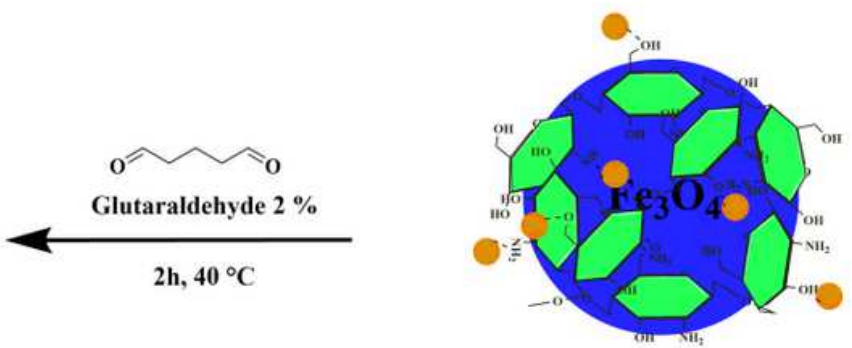

Magnetic chitosan $/ \mathrm{MgO} / \mathrm{Fe}_{3} \mathrm{O}_{4}$ beads $\left(\mathrm{CTS} / \mathrm{MgO} / \mathrm{Fe}_{3} \mathrm{O}_{4}\right.$ )

\section{Figure 1}

Synthesis steps of CTS-GL/MgO/Fe3O4 biocomposite. 


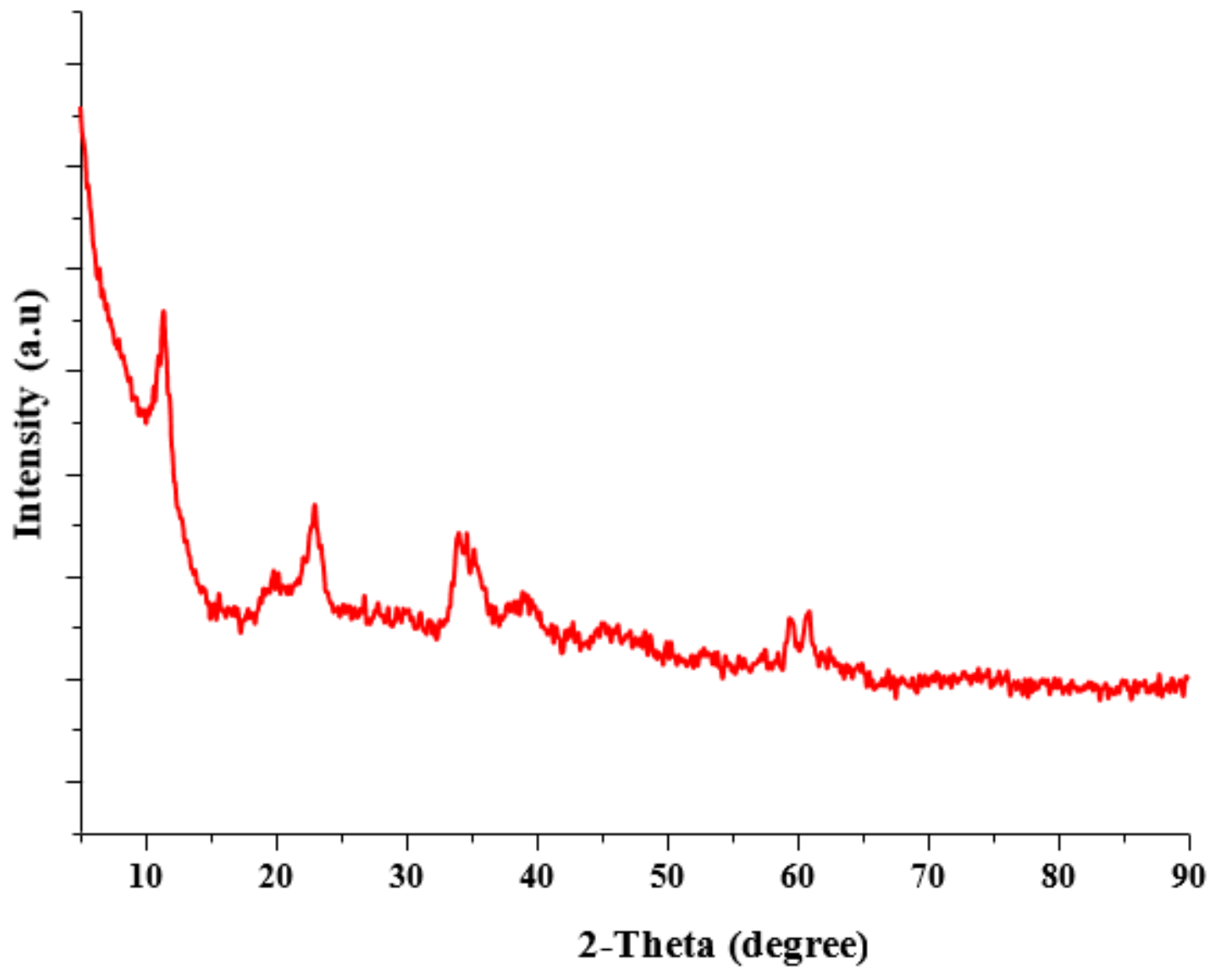

Figure 2

XRD pattern of CTS-GL/MgO/Fe3O4 


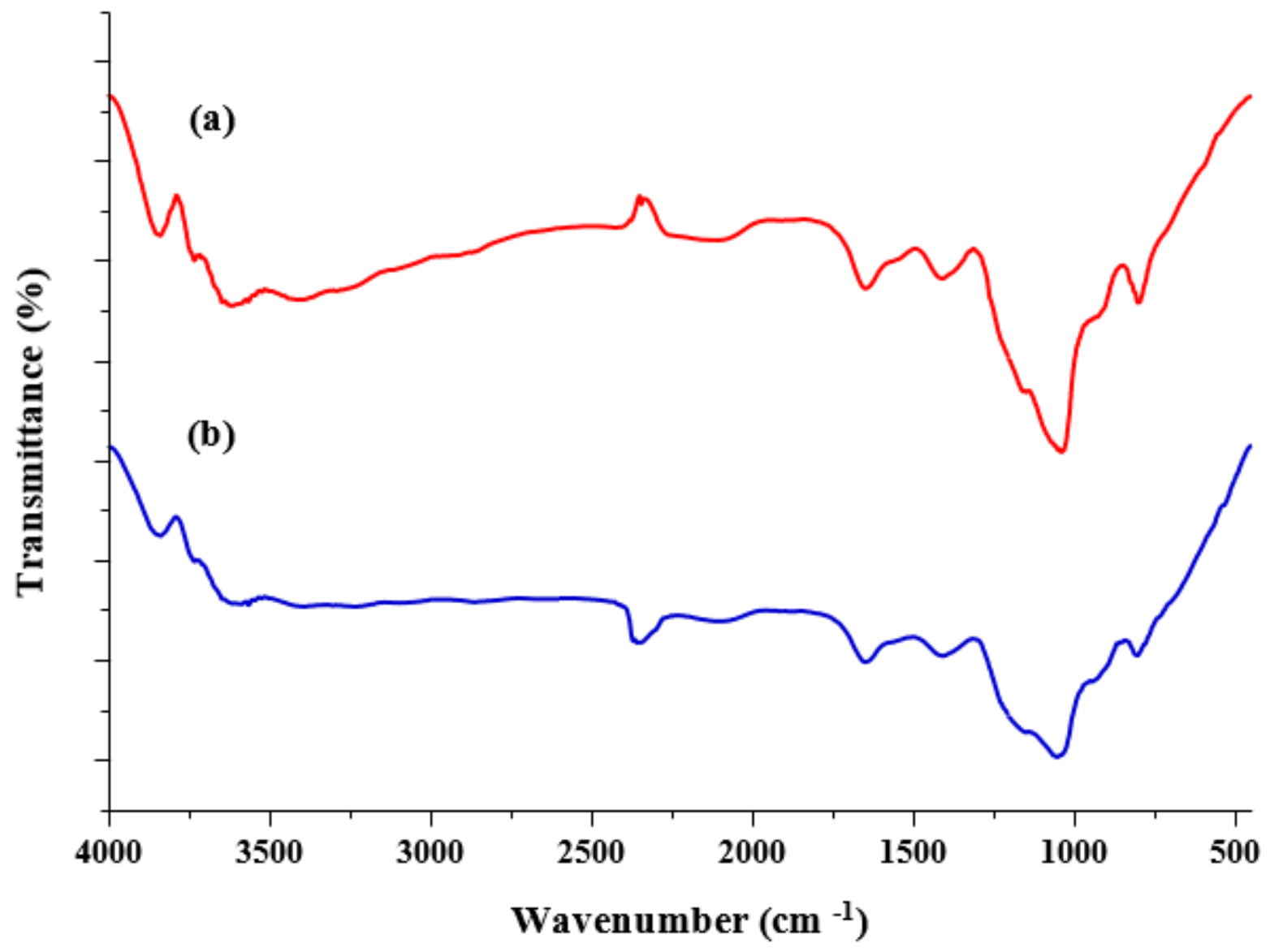

Figure 3

FTIR spectra of CTS-GL/MgO/Fe304 (a) before adsorption and (b) after RB 19 dye adsorption. 

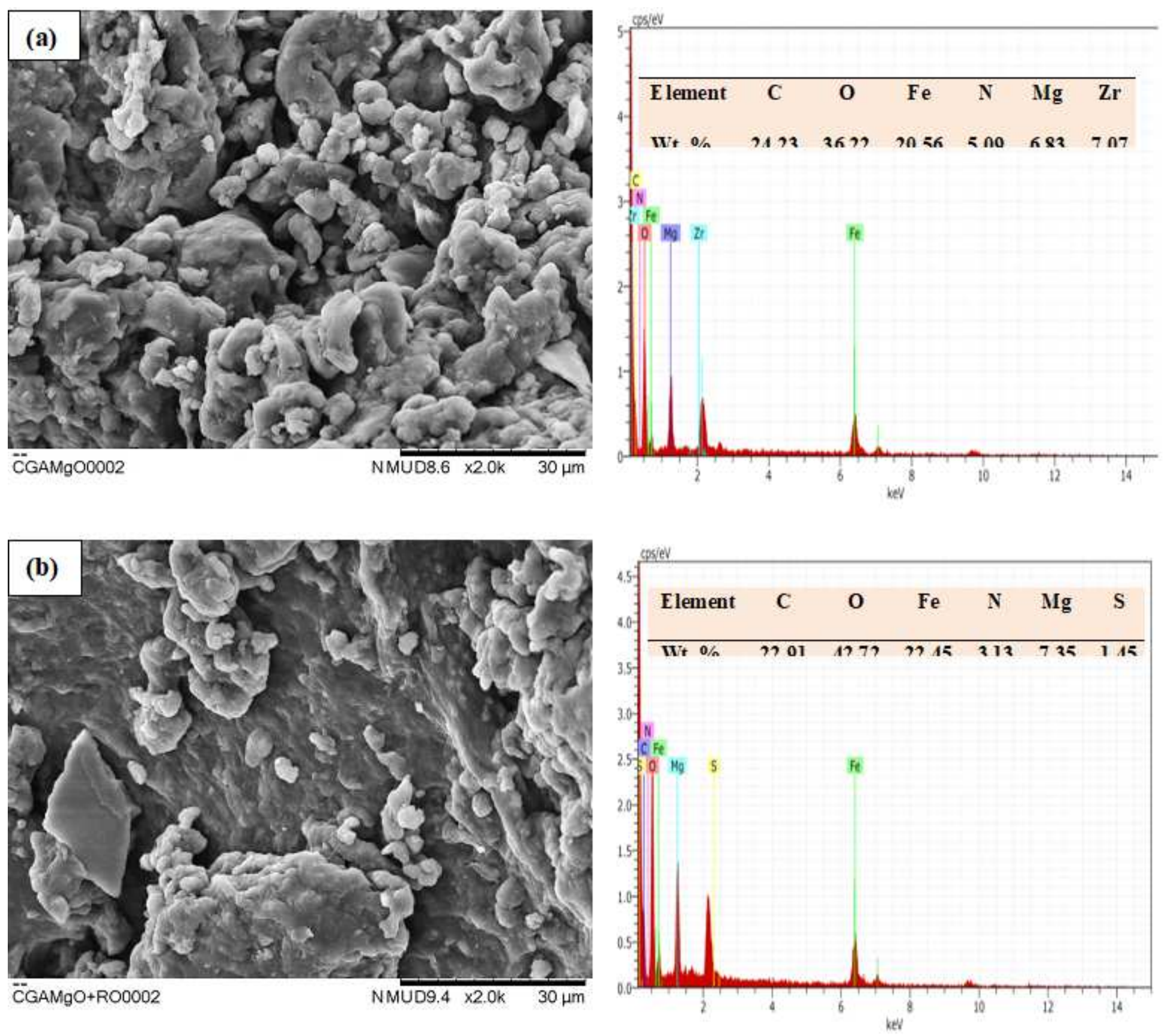

\section{Figure 4}

SEM images and EDX analysis of (a) CTS-GL/MgO/Fe304 and (b) CTS-GL/MgO/Fe3O4 after adsorption of RB 19 dye. 

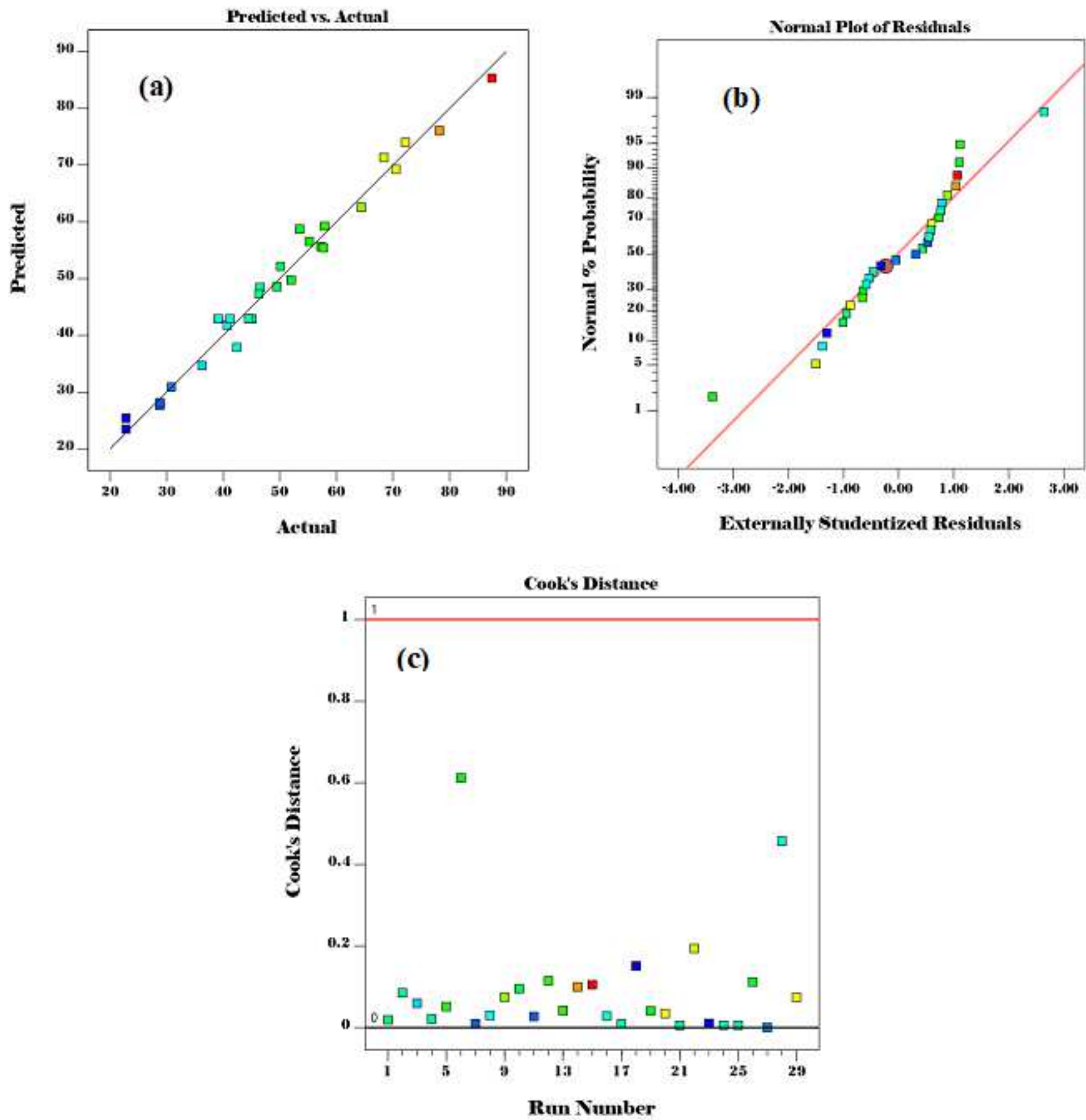

Figure 5

Plots of (a) actual versus predicted, and (b) normal probability of the residuals, (c) the cook's distance for each of the experimental runs. 

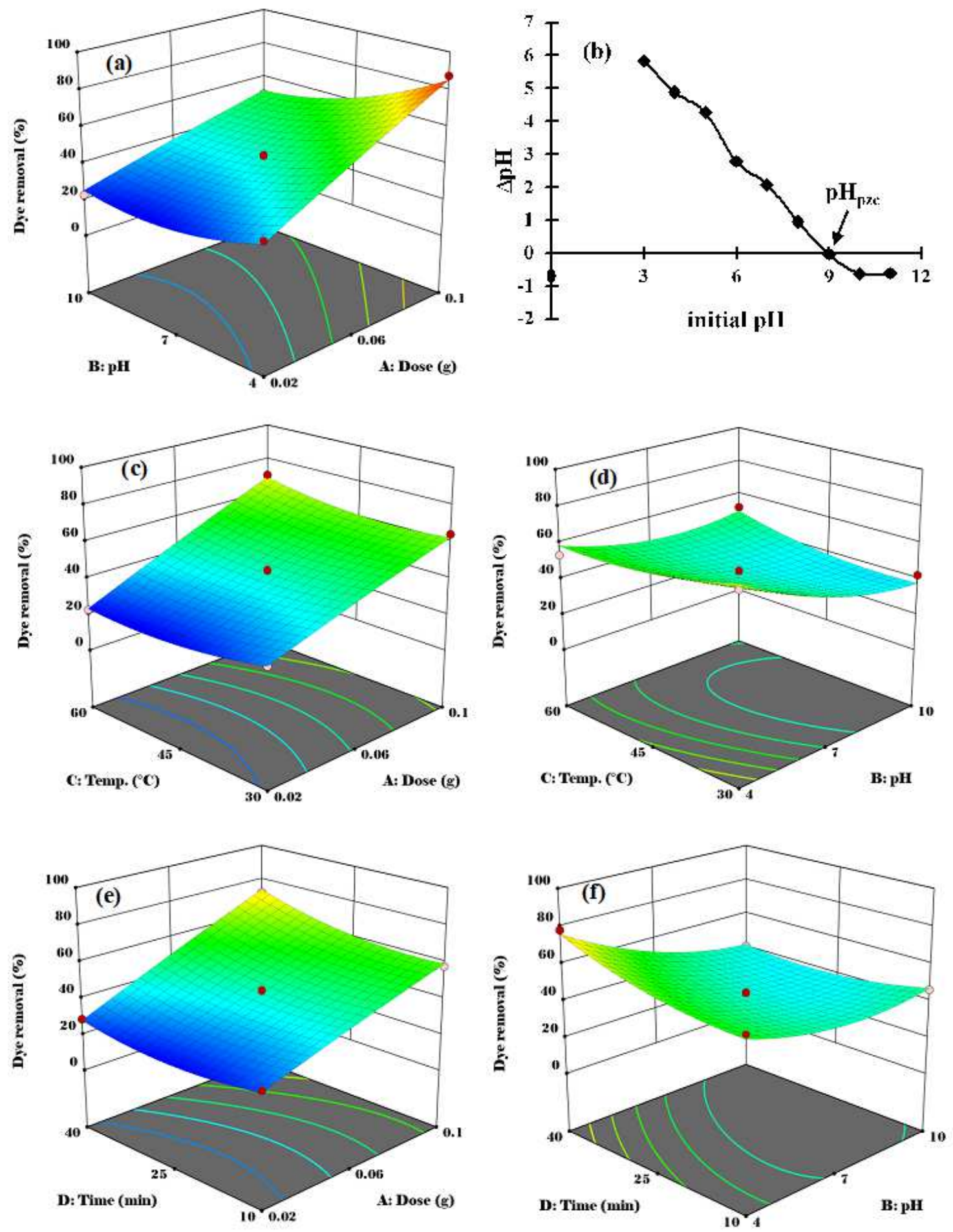

\section{Figure 6}

3D plots of (a) $A B$, (c) AC, (d) AD, (e) BC, and (f) BD significant interactions on dye removal; whereas, (b) pHpzc of CTS-GL/MgO/Fe3O4. 

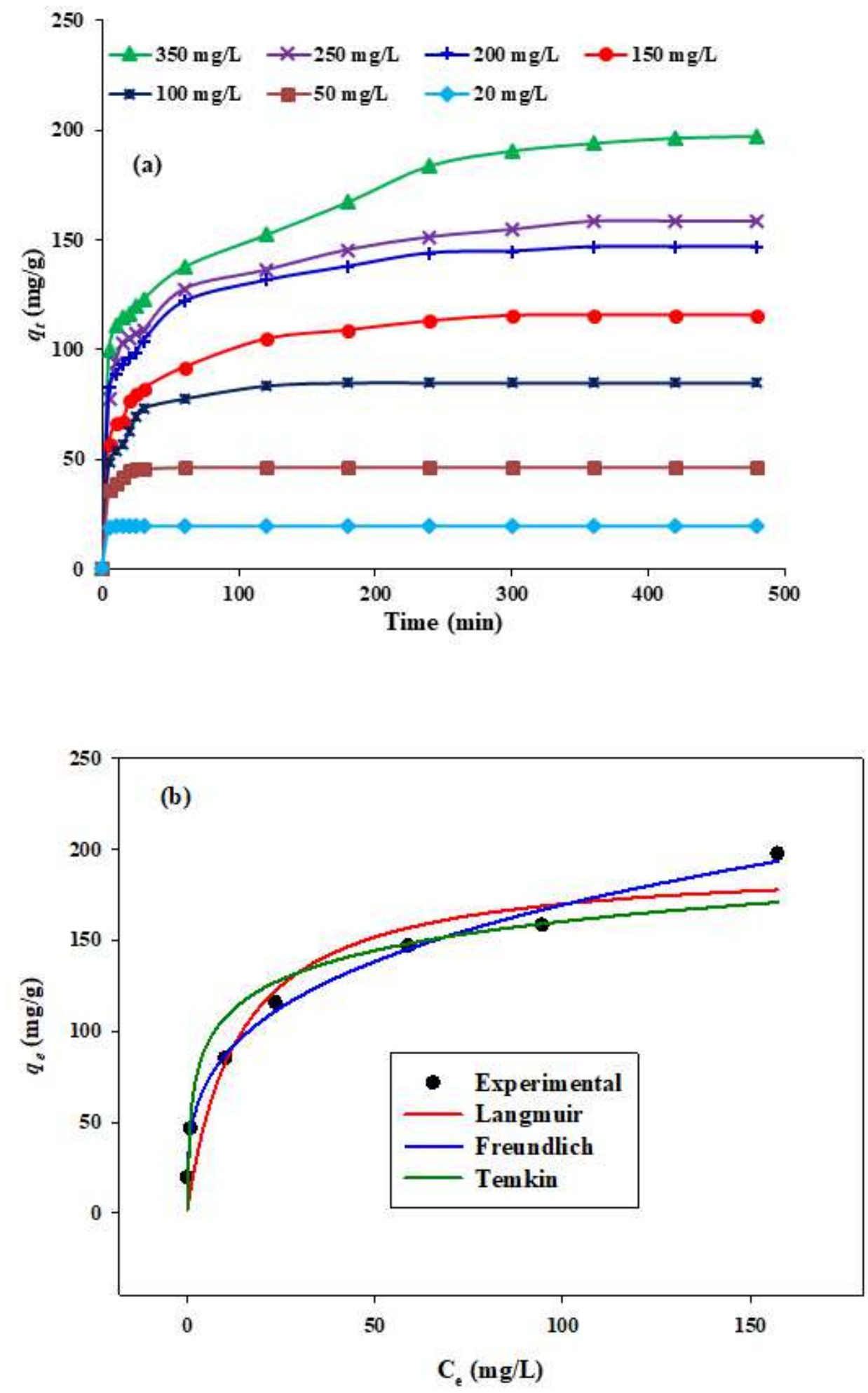

Figure 7

(a) Effect of the contact time on RB 19 dye adsorption at different initial concentrations and (b) adsorption isotherms of dye by CTS-GL/MgO/Fe3O4 (dosage $0.1 \mathrm{~g}, \mathrm{pH}$ of solution 4 , temperature $45 \mathrm{oC}$, agitation speed $=100$ strokes and volume of solution $=100 \mathrm{~mL}$ ). 


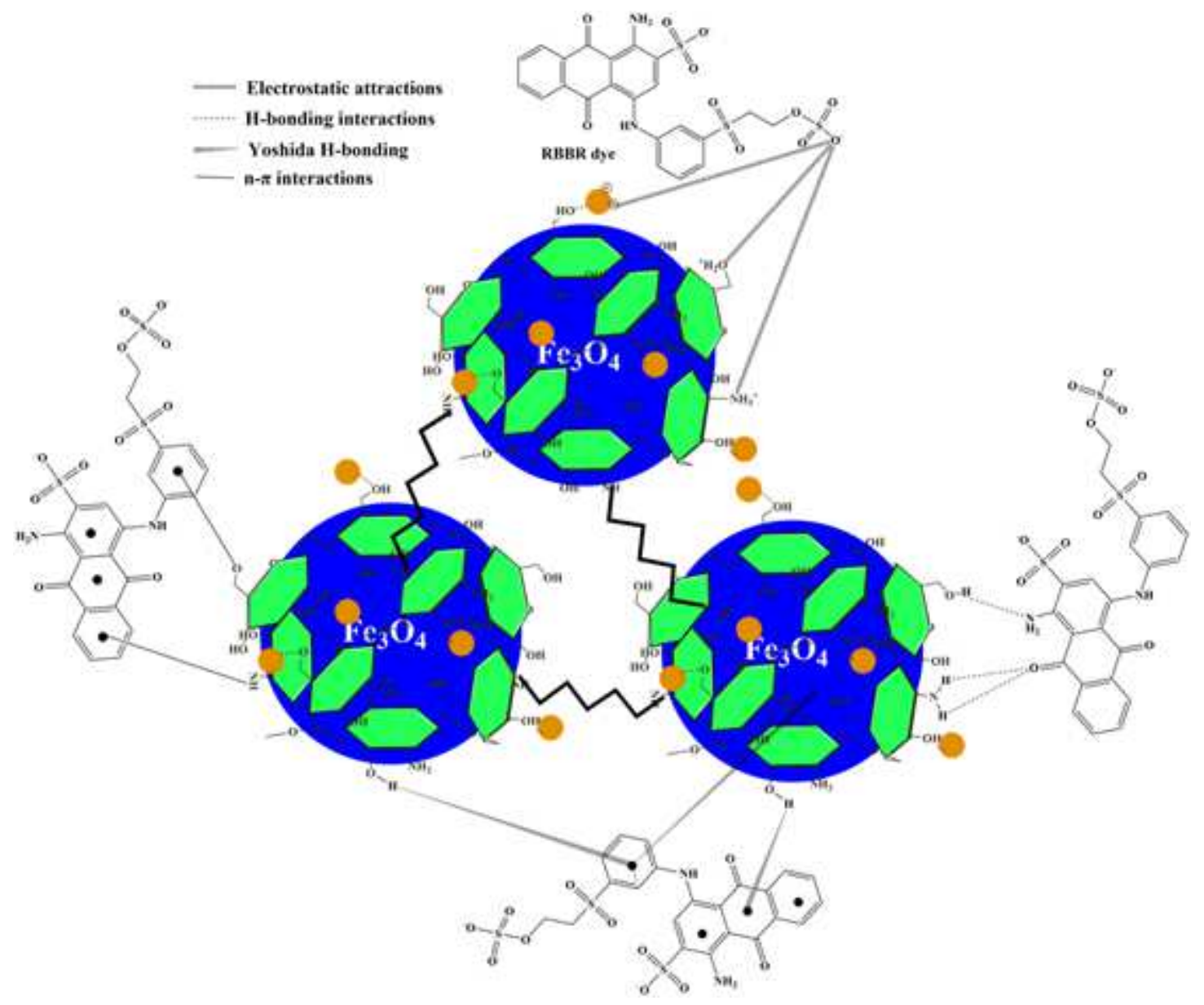

Figure 8

Illustration of the possible interaction between CTS-GL/MgO/Fe3O4 surface and RB 19 including electrostatic attraction, hydrogen bonding interactions, Yoshida $\mathrm{H}$-bonding, and $\mathrm{n}-\mathrm{r}$ interactions. 